\title{
Heterogeneity of pulmonary rehabilitation: like apples and oranges - both healthy fruit
}

\author{
Carolyn L. Rochester ${ }^{1,2}$ and Antonio Spanevello 3,4
}

Affiliations: 'Section of Pulmonary, Critical Care, and Sleep Medicine, Yale University School of Medicine, New Haven, CT, and ${ }^{2}$ VA Connecticut Healthcare System, West Haven, CT, USA. ${ }^{3}$ Pneumology Unit, Fondazione Salvatore Maugeri, IRCCS Tradate, Tradate, and ${ }^{4}$ Dept of Clinical and Experimental Medicine, University of Insubria, Varese, Italy.

Correspondence: A. Spanevello, Pneumology Unit, Fondazione Salvatore Maugeri, IRCCS Tradate, Via Roncaccio 16, Tradate (VA), 21049, Italy. E-mail: antonio.spanevellodafsm.it

@ERSpublications

Worldwide pulmonary rehabilitation provision is heterogeneous and relatively few patients are referred to programmes http://ow.ly/tYg4R

Pulmonary rehabilitation is an essential component of comprehensive integrated care, and indeed is one of the most effective interventions, for persons with chronic obstructive pulmonary disease (COPD) and other forms of chronic respiratory disease [1-4]. It has been convincingly demonstrated to improve patients' exercise tolerance [4,5], symptoms of dyspnoea [6] and quality of life [1], and to reduce anxiety, depression [7], hospitalisations for COPD exacerbations [1, 8, 9] and urgent healthcare utilisation [10]. It is effective even for persons with complex medical comorbidities such as concurrent cardiovascular and metabolic disease [11] and for chronically critically ill persons admitted to intensive care units [12]. Several published guidelines and statements on the science and optimal implementation of pulmonary rehabilitation exist [1, 13-17]. However, despite the extensive knowledge and published evidence base regarding its benefits pulmonary rehabilitation remains severely underutilised worldwide.

In this issue of the European Respiratory Journal, SPRUIT et al. [18] report the findings of a 12-question survey, adapted from an existing survey of pulmonary rehabilitation $[19,20]$, regarding the content and organisational aspects of pulmonary rehabilitation programmes from 430 centres from 40 countries. The majority of respondents were from Europe and North America. The authors found a wide degree of heterogeneity in the content, components, structure and organisation of pulmonary rehabilitation programmes worldwide. Heterogeneity was found in terms of pulmonary rehabilitation programme setting, duration, source of funding and payer reimbursement, number and type of team members, referral sources, patient types, interventions provided, and outcomes measured. The authors conclude that it is important for pulmonary rehabilitation providers to consider development of uniform performance and process metrics to optimise quality control and improve the ability to compare outcomes of clinical trials conducted in differing pulmonary rehabilitation settings.

Several factors likely underlie the programmatic heterogeneity identified in the study by SpRUiT et al. [18]. The variation in funding sources reflects differences in healthcare systems across countries. Universal government-sponsored health insurance exists in some places, whereas a mix of government and private insurance coverage exists elsewhere. Many people worldwide lack health insurance coverage altogether. Irrespective of the funding source, in general, funding for pulmonary rehabilitation programmes and insurance reimbursement for patient participation in these programmes remains suboptimal and should be increased. Lack of funding is widely considered to be a principal obstacle to provision of pulmonary

Received: Jan 312014 | Accepted after revision: Feb 192014

Conflict of interest: Disclosures can be found alongside the online version of this article at www.erj.ersjournals.com 
rehabilitation; it limits the number of programmes available as well as the scope of services that can be provided in individual pulmonary rehabilitation programmes. While the scientific community is committed to producing data demonstrating new models of pulmonary rehabilitation to be delivered with proven clinical outcomes and low costs [21], increased funding and reimbursement is paramount to improving access to pulmonary rehabilitation for patients who can benefit from it.

Heterogeneity in referral practices, both in terms of the types of practitioners who refer patients and the types of patients referred, likely reflect varying knowledge, attitudes and perceptions of pulmonary rehabilitation. Variations in the type and number of team members, as well as the scope of services, types of exercise training and education provided in pulmonary rehabilitation programmes likely relate to funding, accessible space, infrastructure, available providers and local support for the programmes. Despite widespread inclusion and recognition of the vital role of education interventions in pulmonary rehabilitation, wide variation exists in the content and the method of delivery of these interventions [22,23]. More studies are needed assessing the impact of the educational element of pulmonary rehabilitation in comparison to the exercise training component [14].

What are the potential consequences and impact of the heterogeneity of pulmonary rehabilitation programmes identified in the study by SPRUIT et al. [18]? First, the variability in resources available for pulmonary rehabilitation in different regions and countries creates healthcare disparities. The finding that only 34890 patients were enrolled in pulmonary rehabilitation in 2011 across the 430 centres studied, with a median of 40 to 75 patients enrolled per programme, is strong evidence that a vast number of individuals with potential to benefit from pulmonary rehabilitation either are not referred, not enrolled, lack access, or choose not to participate [18]. Consider, for example, World Health Organization estimates that 65 million people have moderate-to-severe COPD [24], the small numbers of patients enrolled in pulmonary rehabilitation across several countries in the current study illustrates that there are a huge number of missed opportunities for patients to benefit from the pulmonary rehabilitation process worldwide. Further, the low number of patient referrals from cardiologists is troubling, since so many patients with cardiovascular disease have concurrent COPD.

Second, variations in programme components, content, duration, staffing, equipment, space, infrastructure and funding have the potential to impact patient outcomes. One might speculate that smaller programmes of limited scope with fewer resources might not be able to provide comparable outcomes to better-funded programmes with multi-specialty interdisciplinary teams operating in specialised rehabilitation centres. While there is some evidence suggesting that programmes longer than 12 weeks in duration may have more durable benefits than shorter programmes [1], there is no definitive evidence that patients who attend smaller programmes achieve lesser gains than those who attend larger, more comprehensive ones. Importantly, because patients with chronic respiratory diseases typically have multiple medical comorbidities and multiple factors contributing to their symptoms and functional limitations, the scope of pulmonary rehabilitation services provided, as well as the site and resources available, impact the types of patients that can be accommodated safely in a pulmonary rehabilitation programme.

Third, the heterogeneity of pulmonary rehabilitation programmes may indeed impact the ability to generalise the results of clinical research trials in this area.

Arguably, the most crucial issue regarding the scope of services provided in pulmonary rehabilitation programmes is quality control. Given healthcare environments with limited resources, we must ensure that what is "sold" as pulmonary rehabilitation includes its core components: patient assessment, exercise training, self-management education and outcomes measurement. Accreditation systems are one means of ensuring quality control, and this is perhaps an important means of establishing process and performance metrics for pulmonary rehabilitation programmes. The precise way of delivering these services may, however, be less important than whether or not the services are provided. Pulmonary rehabilitation providers must be well trained and experienced in provision of the core processes, and must be able to communicate effectively and partner with patients to impact long-term behaviour changes across multiple domains. The standardisation of pulmonary rehabilitation programme staffing per se is likely less important than proper training and motivation of professionals for achieving results [25].

Several additional important points warrant mention. First, given the significant heterogeneity in pulmonary rehabilitation programmes, it is quite striking that the outcomes and multifaceted benefits are so dramatically consistent across innumerable clinical studies conducted in many different settings [1, 13-17]. Second, to some degree, flexibility and adaptability of pulmonary rehabilitation programmes can be advantageous. For example, home-based pulmonary rehabilitation may be best suited to patients who lack access to or are unable to get to hospital-based outpatient programmes, and may promote long-term adherence to health enhancing behaviours by virtue of training patients in the context of their daily home 
environments. Third, observed reductions in depression and anxiety (present in almost half of COPD patients) after pulmonary rehabilitation [7] can improve patients' outcomes [1]. SpRUIT et al. [18] demonstrate that although psychologists are frequently part of the staff of pulmonary rehabilitation programmes, depression and anxiety outcomes are not often reported, particularly in Europe.

This study by SPRUIT et al. [18] illustrates the need for future research regarding the impact of programme heterogeneity, patient participants (e.g. type of underlying disease), individual components and scope of pulmonary rehabilitation services on several clinical outcomes, including, but not limited to, gains in exercise capacity, symptoms, quality of life, healthcare utilisation, and long-term adoption of healthenhancing behaviours such as physical activity. There is also an urgent need to learn more about how to best translate the science and proven benefits of pulmonary rehabilitation into its routine implementation in clinical practice in diverse countries and settings. The basis for the relatively low number of survey respondents from countries other than Europe or North America is unclear. It may reflect lack of available programmes, language or other logistical barriers to providing a response to the survey, cultural and/or knowledge barriers or a combination of these factors. Translation of pulmonary rehabilitation literature into other languages, efforts to disseminate it and use of novel approaches such as telemedicine technologies may also help to facilitate implementation of pulmonary rehabilitation in regions where it is currently lacking.

In conclusion, pulmonary rehabilitation is recommended for patients with several forms of chronic respiratory disease based on its positive impact on functional status, symptoms, quality of life and other important outcomes $[1,3,26]$. Given the variability in healthcare systems across the world, it is not surprising that heterogeneity exists in the provision of pulmonary rehabilitation services across regions, countries and continents. Still, relatively few patients are referred for or enrolled in pulmonary rehabilitation, and important healthcare disparity exists for eligible persons who lack access to pulmonary rehabilitation programmes. Major efforts should be made to increase the availability of rehabilitation programmes worldwide for patients with chronic respiratory diseases, and for those with other chronic diseases and comorbidities. Funding and processes are needed to increase programme capacity, patient access and utilisation of pulmonary rehabilitation, while ensuring quality of content, structure and expected outcomes. International policy recommendations for the use and implementation of pulmonary rehabilitation are needed. We agree with SPRUIT et al. [18] that it is essential to maintain pulmonary rehabilitation programme quality, ensure that the core processes of pulmonary rehabilitation are included, and to develop international standards for programmes based on evidence and best practice. In the process, however, we must avoid imposing inflexible standards that make it difficult for programmes to adapt to their local environment, and we must leave room for future evolution of pulmonary rehabilitation in terms of novel processes and outcome measures as the discipline evolves over time.

\section{References}

1 Spruit MA, Singh SJ, Garvey C, et al. An official American Thoracic Society/European Respiratory Society statement: key concepts and advances in pulmonary rehabilitation. Am J Respir Crit Care Med 2013; 188: e13-e64.

2 Huppmann P, Sczepanski B, Boensch M, et al. Effects of inpatient pulmonary rehabilitation in patients with interstitial lung disease. Eur Respir J 2013; 42: 444-453.

3 Grünig E, Lichtblau M, Ehlken N, et al. Safety and efficacy of exercise training in various forms of pulmonary hypertension. Eur Respir J 2012; 40: 84-92.

4 Rochester CL. Disease-specific approaches in pulmonary rehabilitation. In: AACVPR Guidelines for Pulmonary Rehabilitation Programs. 4th Edn. Champaign, Human Kinetics, 2011.

5 Burtin C, Saey D, Saglam M, et al. Effectiveness of exercise training in patients with COPD: the role of muscle fatigue. Eur Respir J 2012; 40: 338-344.

6 Hill K, Vogiatzis I, Burtin C. The importance of components of pulmonary rehabilitation, other than exercise training, in COPD. Eur Respir Rev 2013; 22: 405-413.

7 Coventry PA. Does pulmonary rehabilitation reduce anxiety and depression in chronic obstructive pulmonary disease? Curr Opin Pulm Med 2009; 15: 143-149.

8 Puhan MA, Gimeno-Santos E, Scharplatz M, et al. Pulmonary rehabilitation following exacerbations of chronic obstructive pulmonary disease. Cochrane Database Syst Rev 2011; 10: CD005305.

9 Seymour JM, Moore L, Jolley CJ, et al. Outpatient pulmonary rehabilitation following acute exacerbations of COPD. Thorax 2010; 65: 423-428.

10 Raskin J, Spiegler P, McCusker C, et al. The effect of pulmonary rehabilitation on healthcare utilization in chronic obstructive pulmonary disease: the Northeast Pulmonary Rehabilitation Consortium. J Cardiopulm Rehabil 2006; 26: 231-236.

11 Crisafulli E, Gorgone P, Vagaggini B, et al. Efficacy of standard rehabilitation in COPD outpatients with comorbidities. Eur Respir J 2010; 36: 1042-1048.

12 Ambrosino N, Venturelli E, Vagheggini G, et al. Rehabilitation, weaning and physical therapy strategies in chronic critically ill patients. Eur Respir J 2012; 39: 487-492.

13 Nici L, Donner C, Wouters E, et al. American Thoracic Society/European Respiratory Society statement on pulmonary rehabilitation. Am J Respir Crit Care Med 2006; 173: 1390-1413.

14 Bolton CE, Bevan-Smith EF, Blakey JD, et al. British Thoracic Society guideline on pulmonary rehabilitation in adults. Thorax 2013; 68: Suppl. 2, iil-ii30. 
15 Ries AL, Bauldoff GS, Carlin BW, et al. Pulmonary rehabilitation: joint ACCP/AACVPR evidence-based clinical practice guidelines. Chest 2007; 131: 4S-42S.

16 Marciniuk DD, Brooks D, Butcher S, et al. Optimizing pulmonary rehabilitation in chronic obstructive pulmonary disease - practical issues: a Canadian Thoracic Society Clinical Practice Guideline. Can Respir J 2010; 17: 159-168.

17 Singh SJ, ZuWallack RL, Garvey C, et al. Learn from the past and create the future: the 2013 ATS/ERS statement on pulmonary rehabilitation. Eur Respir J 2013; 42: 1169-1174.

18 Spruit MA, Pitta F, Garvey C, et al. Differences in content and organisational aspects of pulmonary rehabilitation programmes. Eur Respir J 2014; 43: 1326-1337.

19 Brooks D, Sottana R, Bell B, et al. Characterization of pulmonary rehabilitation programs in Canada in 2005. Can Respir J 2007; 14: 87-92.

20 Brooks D, Lacasse Y, Goldstein RS. Pulmonary rehabilitation programs in Canada: national survey. Can Respir J 1999; 6: 55-63.

21 Holland AE, Mahal A, Hill CJ, et al. Benefits and costs of home-based pulmonary rehabilitation in chronic obstructive pulmonary disease - a multi-centre randomised controlled equivalence trial. BMC Pulm Med 2013; 13: 57.

22 Stoilkova A, Janssen DJ, Wouters EF. Educational programmes in COPD management interventions: a systematic review. Respir Med 2013; 107: 1637-1650.

23 Neri M, Migliori GB, Spanevello A, et al. Economic analysis of two structured treatment and teaching programs on asthma. Allergy 1996; 51: 313-319.

24 World Health Organization. Burden of COPD. www.who.int/respiratory/copd/burden/en/index.html Date last accessed: January 22, 2014

25 Casey D, Murphy K, Devane D, et al. The effectiveness of a structured education pulmonary rehabilitation programme for improving the health status of people with moderate and severe chronic obstructive pulmonary disease in primary care: the PRINCE cluster randomised trial. Thorax 2013; 68: 922-928.

26 Rubin LJ. Exercise training for pulmonary hypertension: another prescription to write? Eur Respir J 2012; 40: 7-8. 